\title{
Force based reliability estimation of remaining cutting tool life in titanium milling
}

Konstantinos Salonitis ${ }^{a,(c o r), ~ A t h a n a s i o s ~ K o l i o s ~}{ }^{b}$,

a Manufacturing Department, Cranfield University, MK43 0AL, UK

b University of Strathclyde, UK

(cor) Corresponding Author: K. Salonitis

E: k.salonitis@cranfield.ac.uk, P: +44(0)1234758347, F: +44(0)1234751172

\begin{abstract}
Reliability estimation and prediction of the remaining life of a cutting tool is paramount for ensuring economic and damage proof machining. Monitoring of the status of the cutting tool and especially flank wear disrupts the process and thus avoided. In the present study a novel reliability estimation approach to the cutting tools remaining life based on advanced approximation methods is proposed. An approximation model that is based on response surface and a surrogate model is used for the representation of flank wear as a function of process parameters and cutting forces. For the establishment of this model, the relationship of cutting forces with flank wear is investigated experimentally. The results show that the proposed method is an efficient method for assessing the reliability of the cutting tool based on the minimum number of experimental runs. Experimental verification for the case of titanium milling confirms the findings of the present study.
\end{abstract}

Keywords: Cutting tool reliability; titanium coating inserts; cutting forces 


\section{Introduction}

Titanium and its alloys are widely used in different industrial sectors such as aerospace, medical, and marine due to their unique properties. Titanium alloys pose advantages such as low density (compared to aluminium and steel, they lie in between), high strength to weight ratio, resistance to corrosion and erosion and high temperature capability in a certain temperature range compared to other metallic materials, that make them widely applied in these fields [1].

Despite of these advantages and wide applications mentioned, a set of challenges in the machining of titanium alloys still exist. Titanium alloys are usually referred to as difficultto-cut alloys due to several reasons. Heat generation at the tool-chip and tool-workpiece interfaces in combination with the low thermal conductivity that limits the capability for heat dissipation, increases the temperature at the tool-workpiece interface. Additionally, the high strength that is maintained at elevated temperature in the tool-material interface leads to rapid tool wear. Chemical affinity with tool materials and rapid work hardening properties also result in low productivity. Finally, built-up formation and low modulus of elasticity are also possible root causes for the difficulties during machining [2], [3]. In figure 1 , the various challenges when machining titanium alloys are mapped.

The industrial practice thus is governed by these limitations, and in general the common understanding is that no matter what machining technique is used, the tool life will be poor. Since heat cannot be easily dissipated, the answer is to reduce as much as possible the heat generated in the first place, and usually this is achieved by minimizing the material stock to be removed per pass. In the aerospace industry though, where the flyto-by ratio is quite high (ranging from 15 to 20), this can have a great impact on the productivity.

In general, the two stakeholders in machining are the machine tool and the cutting tool. With the improvement of machine tools, cutting tools development has become one of the critical factors that have great influence on titanium machining [2] and in most of the cases being the limiting factor in improving productivity. The expectations thus on cutting tools are tough. Indicatively, high hot hardness is required to resist the high stresses involved, good thermal conductivity to minimize thermal shock, good chemical inertness to avoid reacting with titanium, and good toughness and fatigue resistance [3]. These requirements drive the research for cutting tools development in different aspects such as tool material, coatings technology and cooling techniques. 
Specifically, cooling strategies for titanium machining have attracted a wide research interest because of the significant improvement on the tool life as well as the sustainability impact of machining process in general. It is estimated that the cost of cutting fluids is approximately $7-17 \%$ of the total cost in machining processes [4]. During the last decades new alternatives have been developed to improve the tool life. The most widely used are Minimum Quantity Lubrication (MQL) and Cryogenic cooling. The former eliminates large quantities of water and oil-based coolants and replaces them with a small quantity of lubricant mixed with air [5] while the latter is defined as the discipline and technology of working at temperatures below 120K [6]. However, both of these techniques require special design of the cutting tool as they are sensitive to the cutting process environment (lubrication angle etc.) and this topic is out of the scope for this work.

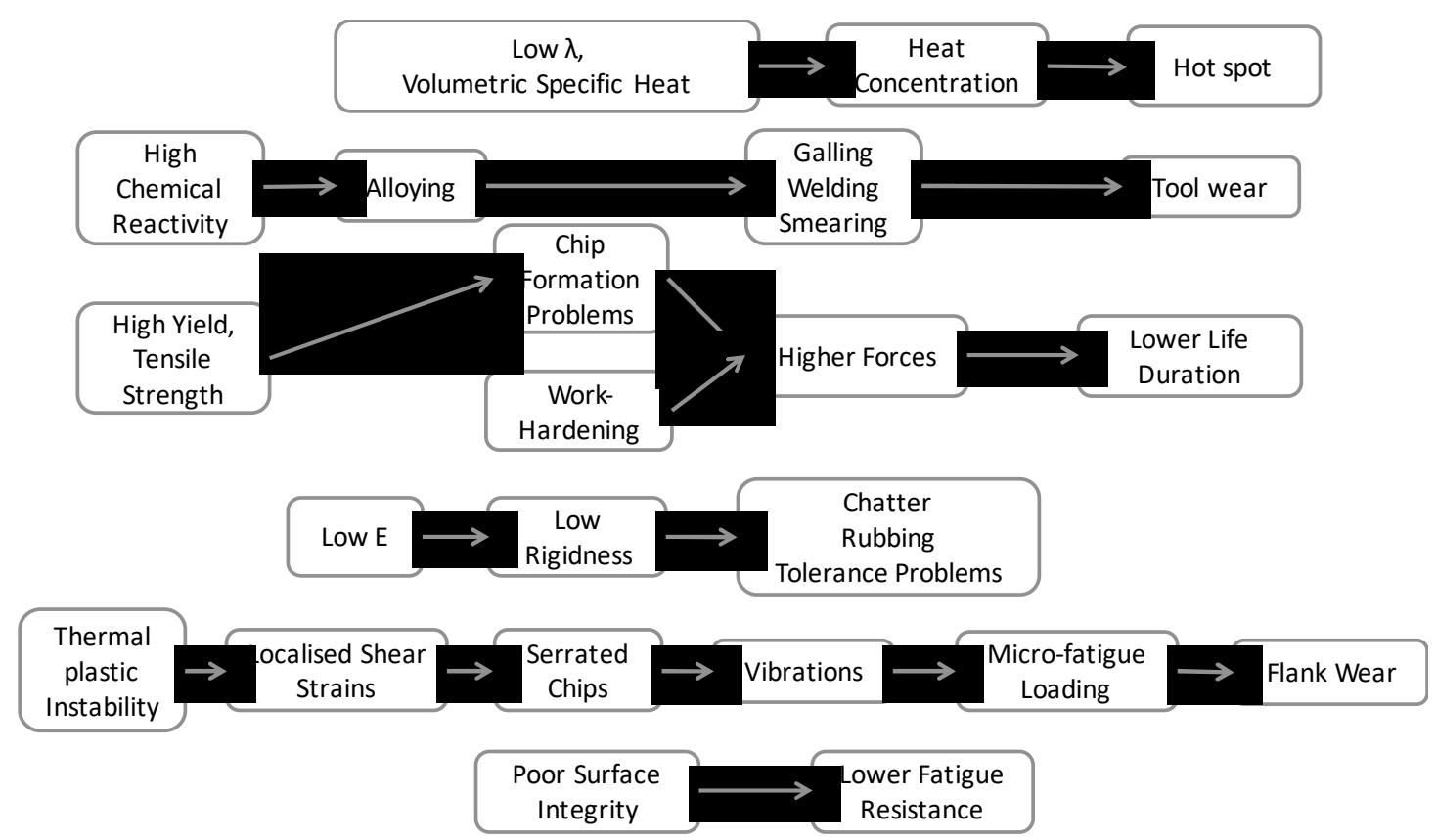

Figure 1: Challenges when machining titanium alloys

As already indicated, one of the key challenges in the machining of titanium alloys is the cutting tool wear that results from the heat generation and the not so "friendly" material properties of Ti alloys for dissipating this heat. However, a number of wear mechanisms can result in the deterioration of the performance of the cutting tool. The studies in this field have classified wear mechanisms into eight categories, namely adhesive wear, single-cycle deformation, repeated-cycle deformation, chemical, thermal, tribofilm, electrical discharge and atomic [7]. For titanium alloys machining, there are specific key 
tool wear mechanisms that prevail. Diffusive wear is the dominant tool failure mechanism, occasionally accompanied with adhesive wear [8]. Diffusive wear has also been observed during high-speed machining Ti-6Al-4V alloy with straight tungsten carbide tools [9]. Abrasive and adhesive wear were dominant when grinding titanium alloys [10]. When face milling, non-uniform flank wear was the dominant wear mechanism, but coating delamination, galling and adhesion were responsible for the initial wear mechanisms [11]. Non-uniform flank wear has been found to be the dominant wear when high-speed machining as well [12]. Localized flank wear was found to be the predominant tool wear when dry machining titanium alloys [13].

A concept map (figure 2) of the observed cutting tool wear results and causes (tool wear mechanisms) for titanium alloys machining has been developed based on literature review [7], [14] - [16]. As shown in figure 2, all wear mechanisms can be observed, with abrasive wear, though being the dominant one. Abrasive wear usually occurs at the initial stage of cutting processes when the temperature is low, and is due to friction between tool and workpiece. But for coated tools, coating delamination is usually the initial wear mechanism. With the increase of temperature, adhesive wear and diffusive wear occur that lead to flank wear, built-up edge, crater wear, etc. It is important to know that various wear mechanisms occur simultaneously when machining, but generally one of them acts as the dominant wear mechanism.

Tool wear obviously decreases tool life. The shorter the tool life, the more time will be spent in non-adding value activities, such as replacing cutting tools and resetting the machine tool. Furthermore, to ensure that the quality of the final product is maintained, accidental fracture of the cutting tool needs to be avoided. Therefore, for avoiding failures; tools are often replaced well before the end of their useful lifetime. It has been reported that only $50-80 \%$ of the expected tool life is typically used [17]. For difficult to cut materials, this results in increasing the cost of tooling, and can be up to $25 \%$ of the total machining cost [18].

Tool wear as well impacts the accuracy of the process outcome. Dimensional accuracy and surface quality are impacted by the state of the tool. Previous studies have shown that tool wear impacts the flatness and requires advanced models for its compensation [19]. Surface roughness as well is affected by tool wear [20]. Surface roughness however is quite complex to be modelled independently to the process dynamics and using simple kinematic-geometric models can considerably underestimate its value [21]. 


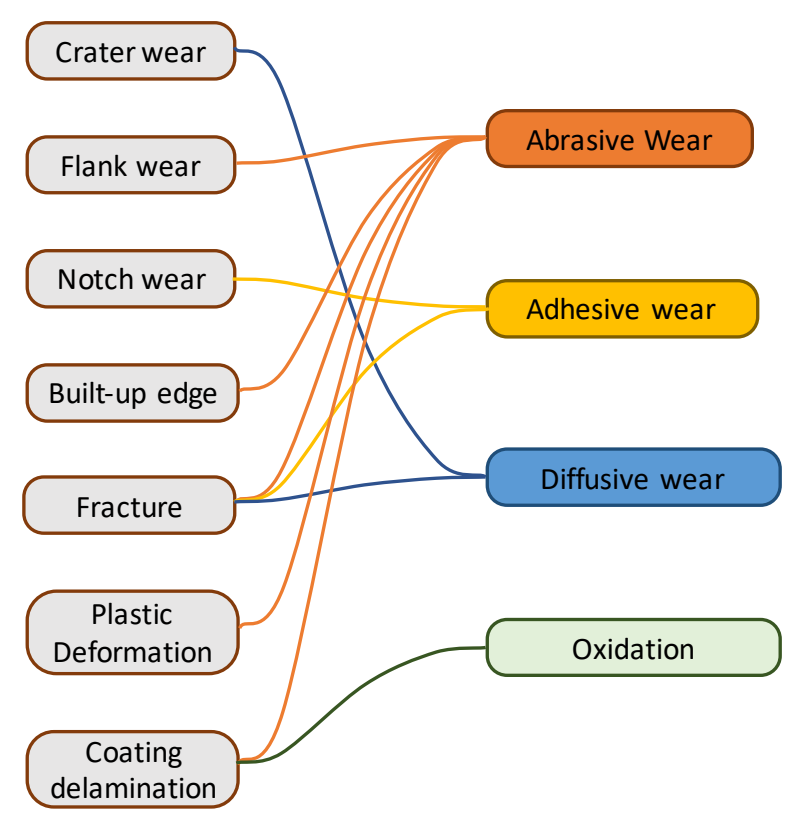

Figure 2: Tool wear concept mapping for titanium alloys machining linking tool wear and cause and result

As shown in figure 2, several wear results can be observed that can be correlated to different wear mechanisms such as abrasion, adhesion, oxidation, diffusion etc. On most occasions, these wear mechanisms operate simultaneously in a machining process. The dominant wear mechanism depends on the cutting conditions and tool / workpiece materials. El Wardany and Elbestawi [22] correlated the prevailing wear mechanisms with the cutting parameters. Crater wear for example is attributed to dissolution and diffusion mechanisms [23], [24] and flank wear with adhesive wear [25]. Flank wear is often considered as most important and is used to define the end of effective tool life (with the first attempt being the one reported by Taylor).

Sarhan et al. [26] stated that the tool wear can be measured either directly or indirectly. The direct method obviously relies on measuring the actual wear; the indirect method relies on measuring cutting forces, torque, sound, temperature variation of tools and surface roughness and relate this with the wear. Measuring the flank wear using a microscope is obviously the most accurate way, however this is not ideal when applied in industry. To measure tool wear values, the machining process has to be stopped frequently, have the cutting tool removed, cleaned and measured, and then reset to restart machining. On the contrary, indirect methods, such as measuring cutting forces, can minimize this influence since these methods can be performed while machine tools are still working. 
A typical three stages flank wear trend line during turning titanium alloys Ti-6Al-4V has been proposed in several papers. Flank wear typically increases rapidly at the initial stage, followed by a relatively long stable period and finally increases dramatically at the final stage before fracture [3], [27]. This pattern has also been found when turning titanium alloys Ti-6246 [11]. Similar trend has also been found when milling titanium alloys, where flank wear increased with cutting time [28], [12], [13].

As the goal of the presented study is to use the cutting forces measurements for predicting the remaining life of the cutting tool, a comprehensive literature review of the studies on cutting forces during machining was undertaken. A very large number of papers have investigated different perspectives of cutting forces during machining. The cutting forces in machining with PCD tools show a slow, progressive and gradual increase with the cutting time [29]. When the cutting speed is slow, the cutting force tends to be stable and slowly increases, but it increases remarkably faster with the increase of cutting speed in hard steel turning [30]. The progression pattern of cutting forces is similar to that of the trend of tools wear with cutting speed when turning Inconel 718 [31]. In milling of Ti-6Al$4 \mathrm{~V}$ alloys, the cutting forces components Fx is stable, but Fy and Fz increase with cutting time [32].

Additionally, the relationship between cutting forces and tool wear has also been investigated. Both horizontal and vertical cutting forces exhibit notable increases with tool wear [33]. The tool wear propagation was believed to be responsible for the gradual increase of the mean peak force in successive cutting passes [34]. The mean cutting force increases with the increasing of flank wear [35]. Cutting forces rise rapidly with the increasing of cutting tool wear in titanium alloy turning [26].

Based on the literature review, a cutting parameter influence table can be prepared (Table 1). This table shows the basic relationship between cutting forces, flank wear and three cutting parameters.

Table 1: Relationship between cutting force, flank wear and cutting parameters

\begin{tabular}{|c|c|c|c|c|}
\hline \multicolumn{3}{|c|}{ Causes } & \multicolumn{2}{|c|}{ Results } \\
\hline $\begin{array}{c}\text { Cutting speed } \\
\qquad V_{c}\end{array}$ & $\begin{array}{c}\text { Feed rate } \\
f_{d}\end{array}$ & $\begin{array}{c}\text { Depth of cut } \\
d\end{array}$ & $\begin{array}{c}\text { Cutting force } \\
\qquad F_{c}\end{array}$ & $\begin{array}{c}\text { Flank wear } \\
V_{B}\end{array}$ \\
\hline 仓 & Fixed & Fixed & ת & 仓 \\
\hline Fixed & 仓 & Fixed & 仓 & 仓 \\
\hline Fixed & Fixed & 仓 & 仓 & 仓 \\
\hline
\end{tabular}


The relationship between cutting forces and cutting time can be summarized in Figure 3. Cutting forces increase with cutting time when machining both soft and hard materials, but cutting forces attain higher values and present a sharper increase when cutting hard materials. Examples of hard materials are hard steel, Inconel 718 and titanium alloys, whereas example of soft material is graphite workpiece.

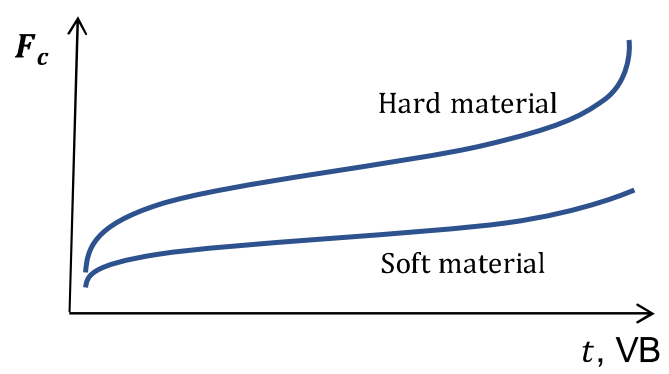

Figure 3: Typical relationship between cutting force and time

Modelling and predicting the tool life is critical. However, as mentioned by Salonitis and Kolios [15], the cutting tool life is characterized by stochasticity and as such there is a need for using reliability techniques. Several numbers of papers have been presented on the reliability of the cutting tool, most of them relying and extending the Taylor equation, as an example, the work presented by Carlson and Strand [36]. Salonitis and Kolios [15], [37] presented a probabilistic approach for the assessment of the tool life performance that is based on a minimum number of fundamental experimental data for cutting speeds and feed rates.

However, these probabilistic approaches are relying on the experimental determination of the cutting tool wear (in most cases the flank wear) to estimate the coefficients of either simplified or extended Taylor equations. Besides the time-consuming process of running a large number of experiments with intervals for either optical microscopic or SEM measurements of the flank wear, these coefficients are useable for specific process parameters and material combinations. Ideally the reliability of the cutting tool should be estimated based on relevant process characteristics that can be linked to the wear and measured online. Such characteristics include the cutting forces and the spindle power, that can be easily monitored while processing.

In the present paper, the authors aim to extend the method proposed by Salonitis and Kolios [15] for estimating the reliability and remaining life of a cutting tool, based 
however on the monitoring of the cutting forces. This is a novel approach that has not presented in any studies published so far. The next section in the paper presents the research methodology developed.

\section{Proposed modelling of cutting tool life and reliability}

The main goal in assessing the reliability of the cutting tool is for making sure that the cutting tool is used for as much as possible without any failures (such as fracture of inserts). Due to the lack of accurate predictions, high safety factors are used, that are usually based on the machine tool operator's experience. Salonitis and Kolios [15], [37] developed a method based on probabilistic and approxiamtion techniques for predicting the reliability of a cutting tool. Their method was based however on experimentally measuring the flank wear of the cutting tool, a practice that is not easy to adapt in an industrial envrionment.

The method proposed in the present study allows the development of an approximation model that is based on response surface and a surrogate model, for the representation of flank wear as a function of process parameters and cutting forces (figure 4). For the establishment of this model however, the relationship of cutting forces with flank wear needs to be determined experimentally.

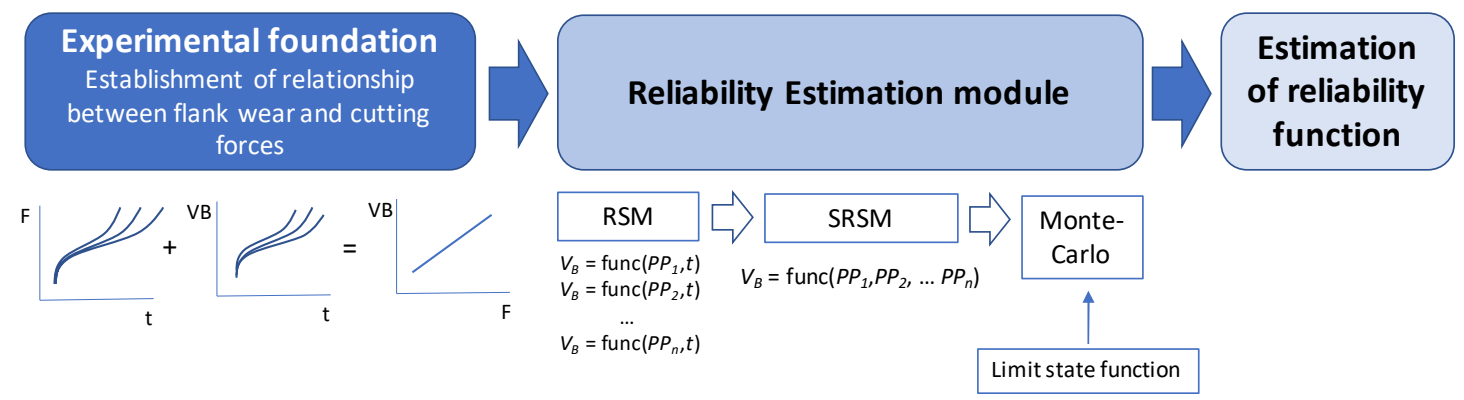

Figure 4: Reliability estimation based on cutting force measurement

Figure 5 shows the proposed approach in more detail. Cutting force functions of cutting conditions are to be obtained by multivariate polynomial regression method. Considering the limit state function, cutting forces are normalized into standard values. Then response surface functions of cutting speed, feed rate at different time are regressed to build limit state functions. Normal distribution is selected and its characteristics are chosen. Finally, Monte Carlo simulation is used as reliability calculation. The various elements of the methodology and their theoretical background are presented in detail by Salonitis and Kolios [15]. 


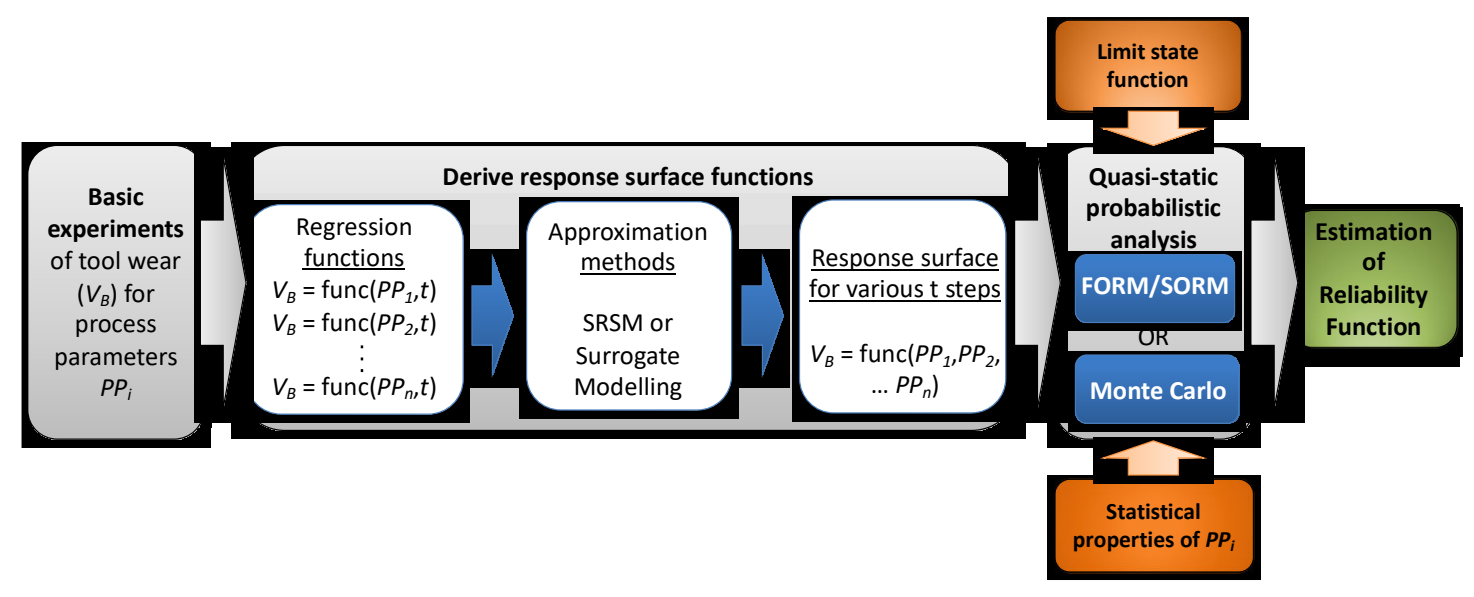

Figure 5: The proposed methodology to assess cutting tool reliability based on cutting forces

\section{Experimental setup}

In order to determine the relationship between the cutting forces and flank wear, a number of experiments were conducted. The workpiece material used for the experiments was Ti-6Al-4V alloy (table 2 and 3 present the material properties and chemical composition respectively).

Table 2: Material properties of selected material

\begin{tabular}{llllll}
\hline $\begin{array}{l}\text { Density } \\
\left(\mathrm{kg} / \mathrm{m}^{3}\right)\end{array}$ & $\begin{array}{l}\text { Young's } \\
\text { modulus } \\
(\mathrm{GPa})\end{array}$ & $\begin{array}{l}\text { Yield } \\
\text { strength } \\
(\mathrm{MPa})\end{array}$ & $\begin{array}{l}\text { Hardness } \\
(\mathrm{HB})\end{array}$ & $\begin{array}{l}\text { Elongation } \\
(\%)\end{array}$ & $\begin{array}{l}\text { Reduction in } \\
\text { area } \\
(\%)\end{array}$ \\
\hline 4430 & 113.8 & 880 & 334 & 14 & 36 \\
\hline
\end{tabular}

Table 3: Chemical composition of selected material

\begin{tabular}{lllllllll}
\hline AL & $\mathrm{V}$ & $\mathrm{Fe}$ & $\mathrm{Si}$ & $\mathrm{C}$ & $\mathrm{N}$ & $\mathrm{H}$ & $\mathrm{O}$ & Titanium \\
\hline 5.60 & 3.86 & 0.18 & $<0.01$ & 0.02 & 0.023 & $<0.01$ & 0.17 & Balance \\
\hline
\end{tabular}

A single flute milling tool was selected for all experiments. The diameter of the tool was $10 \mathrm{~mm}$ with a corner radius of $0.5 \mathrm{~mm}$ and a length of $140 \mathrm{~mm}$ (resulting in a slenderness ratio of 1:14). The mill used can be classified as an end mill one. The tool holder used in was a shrink fit HSK40 one. Cutting tool inserts with two different coatings (a PVD and a CVD one) were used for investigating the importance of the type of coating as well. The PVD coating was a commercial one (TiAlN-TiN). 
The workpiece size was 500x500x150 mm ( $\mathrm{LxWxH}$ ) and was fixed to the milling machine bed with T-slot nuts. The milling process was a raster one with $60 \%$ overlap after each consecutive cut. The feed direction and the rotation of the milling tool resulted in an upmilling operation. During the process, the cooling process selected was floor cooling using an oil based commercial coolant fluid.

The experiments were conducted on a CNC milling machine at Cranfield University. In all experiments, the depth of cut was fixed at $3 \mathrm{~mm}$. Six set of experiments were conducted with different process parameters varying the cutting speed (from 75 up to $125 \mathrm{~m} / \mathrm{min}$ ) and the feed rate (from 0.08 to $0.12 \mathrm{~mm} /$ tooth). During the experiments, the cutting forces were monitored with a piezoelectric multicomponent dynamometer attached to the milling machine bed. The three force components were measured as shown in figure 6. $F_{x}$ indicates perpendicular direction of cutting direction, $F_{y}$ indicates cutting direction and $F_{z}$ indicates vertical direction along spindle. The dynamometer used has a great rigidity and consequently a high natural frequency, which enables very small force changes to be measured. The cutting forces were measured with a sapling frequency of $5 \mathrm{KHz}$. High efficiency shielded cables are used to reduce noise. Kalman filter was used to remove any noise due to structural modes on the force measurements. Furthermore, the measured signals were detrended, where the mean value of each measurement was subtracted and normalized. Both FFT (Radix-2 method) and CWT (Morlet wavelet) analysis were conducted on the cutting force data. The dominant features were obtained to predict the tool condition. However, the frequency analysis of the signals are not within the scope of the present study.

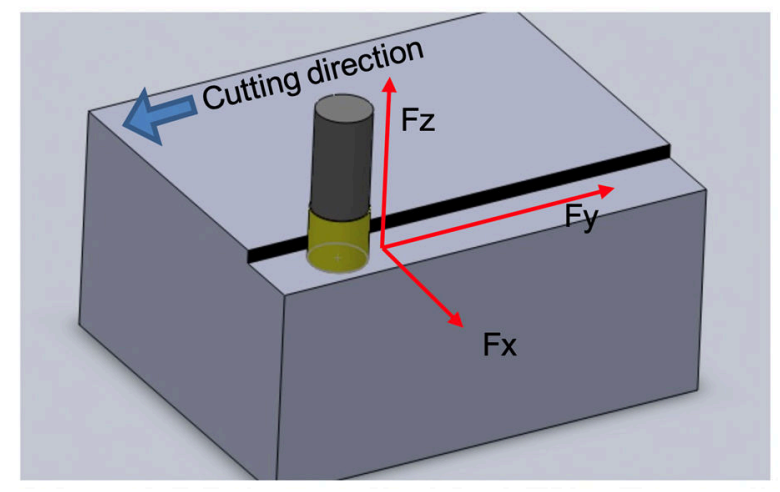

Figure 6: Explanation of cutting force components when measuring by the multicomponent dynamometer in the experiments 
The tool wear was measured using an optical microscope every 2.5 minutes of real cutting. For each measurement, five sample measurements were taken in order to minimize statistical errors. The wear flank value reported is the average value of these five measurements. The flank wear was measured according to ISO 3685:1993 standard [38]. An example of the optical measurement of the flank wear performed, as well as photographs of the rake face, are shown in figure 7.
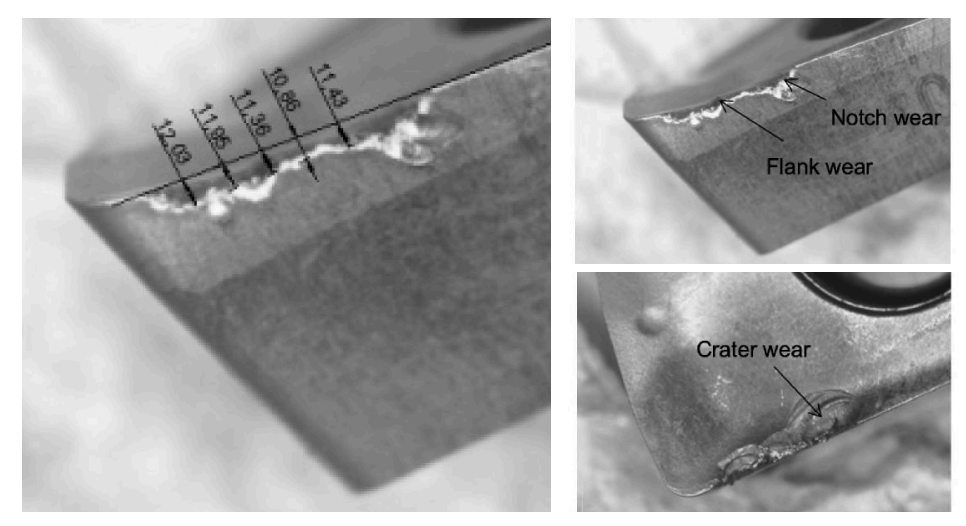

Figure 7: Example of cutting wear measurement in the optical microscope

\section{Experimental results, analysis and discussion}

The measurements conducted for the two different inserts are shown in figure 8 . Generally, flank wear increases with cutting time, and has the typical three stages progression trend as it was expected. This result fits well with investigations from previous researches on titanium alloys milling [12], [13], [28]. Moreover, titanium based coating insert perform better than that of aluminium oxide based coating insert. Setting the tool life criterion to be $0.3 \mathrm{~mm}$, i.e. when the wear flank reaches this value, the tool life ends, it is evident that titanium based coated cutting tools have a longer tool life compared to the other one.

Simultaneously, the cutting force was measured with a piezoelectric dynamometer. Similar trend to the evolution of the flank wear is shown for both types of cutting tool coating, proving that cutting force can be used for the direct assessment of the flank wear. Average forces increase with cutting time as it was expected. The measurements in figure 8(b) are the average values. Three cutting force components were measured by the dynamometer as well. It can be seen by the results presented in figure 9 , that the force component along the cutting direction is the most dominant one, and follows the pattern 
of the evolution of the flank wear as well. It is safe thus to neglect the other two components. However, for the needs of the present study the total force is going to be used for the calculations.
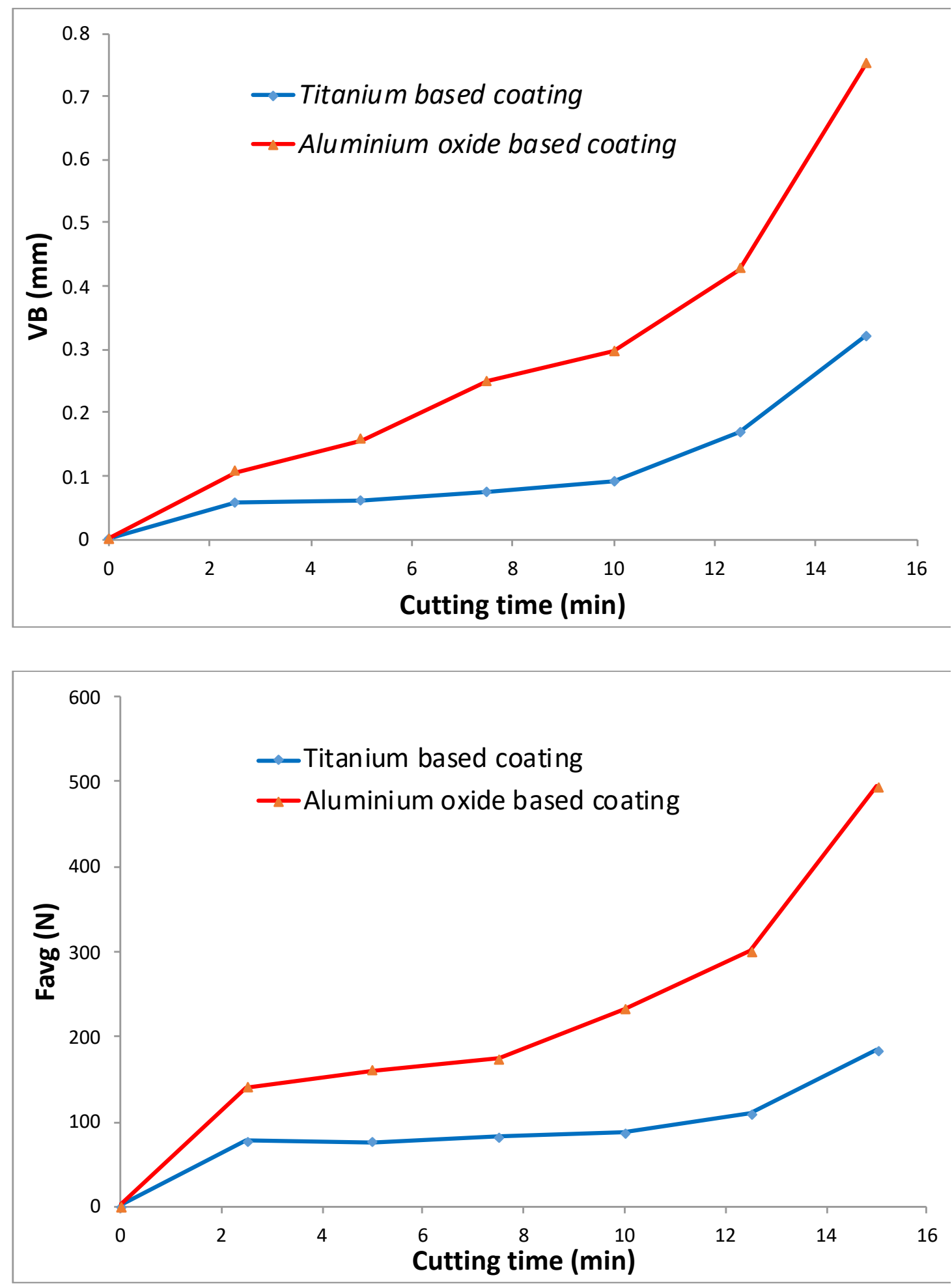

Figure 8: (a-top) Average flank wear measurements and (b-bottom) cutting force as a function of cutting time $\left(V=100 \mathrm{~m} / \mathrm{min}, F_{d}=0.1 \mathrm{~mm} /\right.$ tooth, $d=3 \mathrm{~mm}$, Stepover $=3 \mathrm{~mm}$, Cooling: flood $)$ 

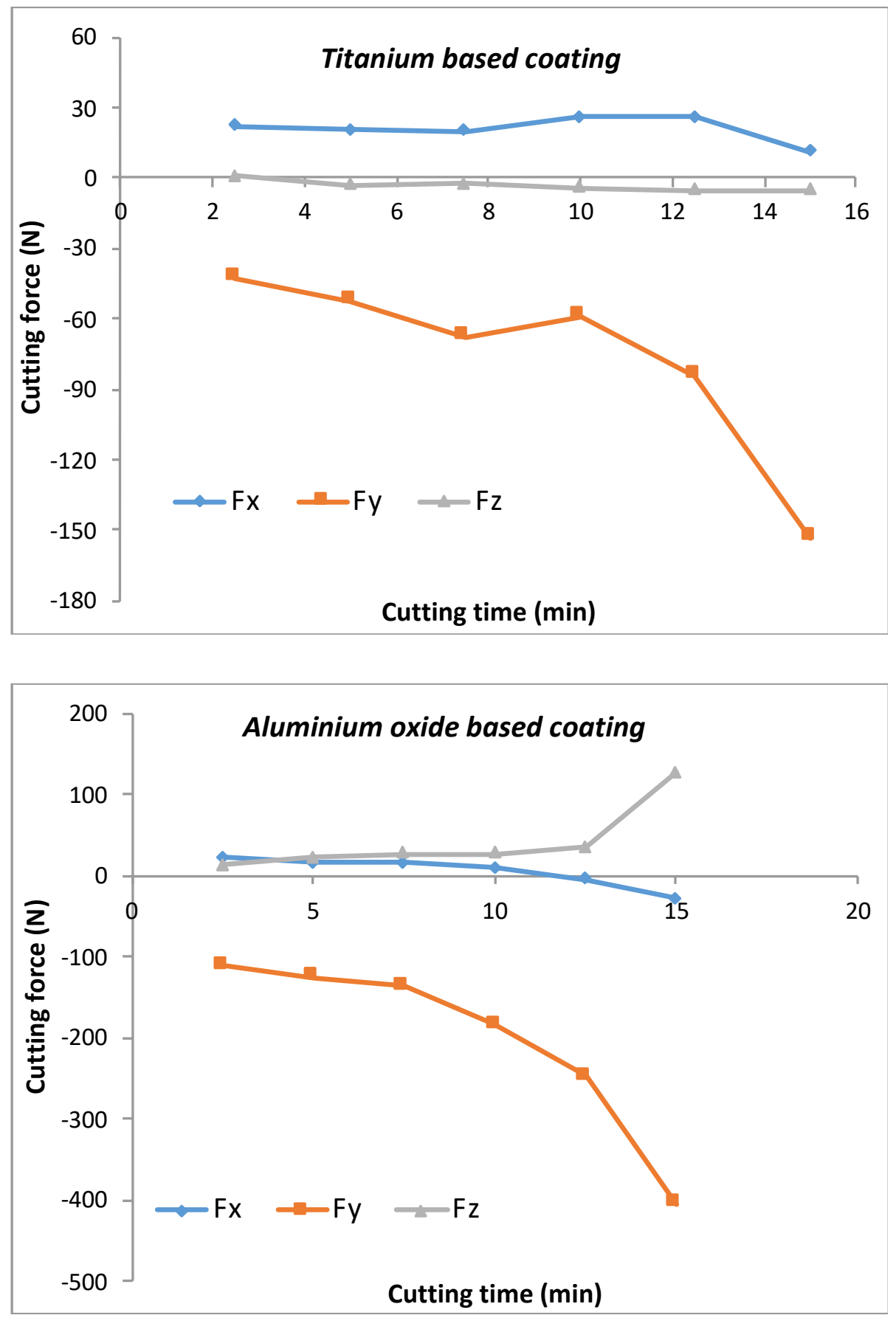

Figure 9: Evolution of the three cutting force components $\left(V=100 \mathrm{~m} / \mathrm{min}, F_{d}=0.1 \mathrm{~mm} /\right.$ tooth,$d=3$ $\mathrm{mm}$, Stepover $=3 \mathrm{~mm}$, Cooling: flood) $-F_{x}$ indicates perpendicular direction of cutting direction, $F_{y}$ indicates cutting direction and $F_{z}$ indicates vertical direction along spindle. Moving average of the cutting forces is presented.

The process parameters also have a significant effect on both the cutting parameters and wear flank. In figure 10, the cutting force measurements for the titanium coated cutting tools is presented for several different process parameters combinations. Increasing the cutting speed, as it is to be expected, results in higher cutting forces and the tool fails sooner. Similar trends are shown when increasing the feed per tooth. 

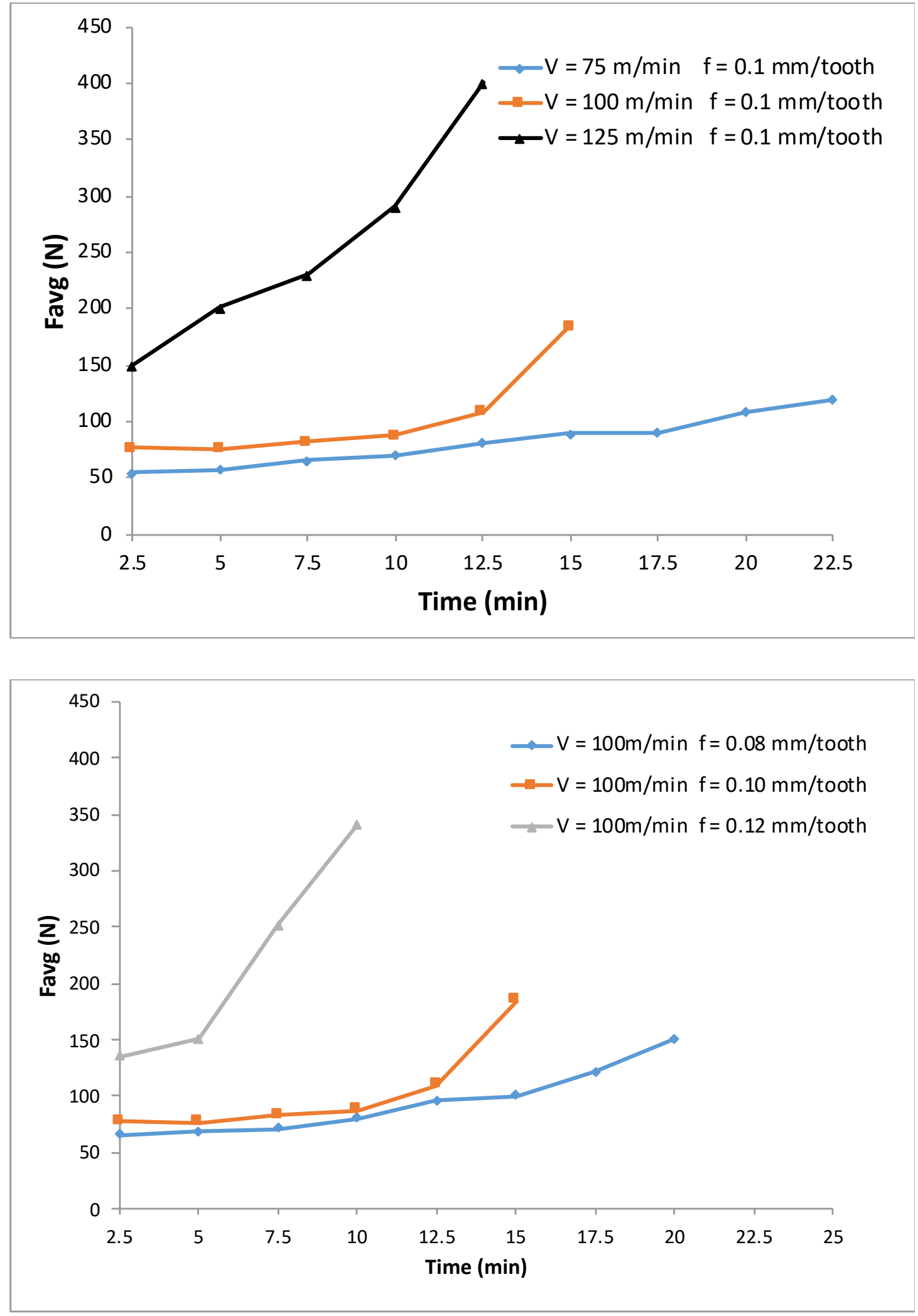

Figure 10: Cutting forces measurement for the titanium based coated cutting tool (top-feed speed steady, bottom - cutting speed steady) 
Correlating the average cutting force with the average flank wear, based on the obtained results, is thus obvious. Figure 11(a), presents this correlation for the results presented in figure 8. However, as mentioned previously this correlation could be also performed if the cutting direction component of the force was used and not the total. Linear regression models are shown to be a very good way to express this relationship and R-square indicates the goodness of fit. This is in agreement to previous findings for other type of materials as well. For example, Wojciechowski and Twardowski [39], shown similar linear relations for the of milling of hardened steel using sintered carbide and cubic boron nitride cutting tools. It needs to be highlighted though that such a correlation has a specific limitation; it relies on the selected process parameters combination. Since increasing for example the cutting speed will result in reduced cutting forces. Normalizing the cutting force thus can prove to be a way for more easily reaching conclusions. A number of different normalization approaches were tested, with the most promising one being normalizing the force to the initial average force measurements for a brand new cutting tool insert. In figure 11(b) this correlation is shown graphically. By normalizing the experimental data, cutting forces of each experiment start from 1 , it enables the easy comparison of all data in all experiments with the same standard. Moreover, like setting failure criteria of flank wear, a failure criteria value of cutting force can be set by normalizing. For example, if setting 2 as the failure criteria of normalized cutting force, it enables us to clearly know when the cutting force will reach double of the initial value. 

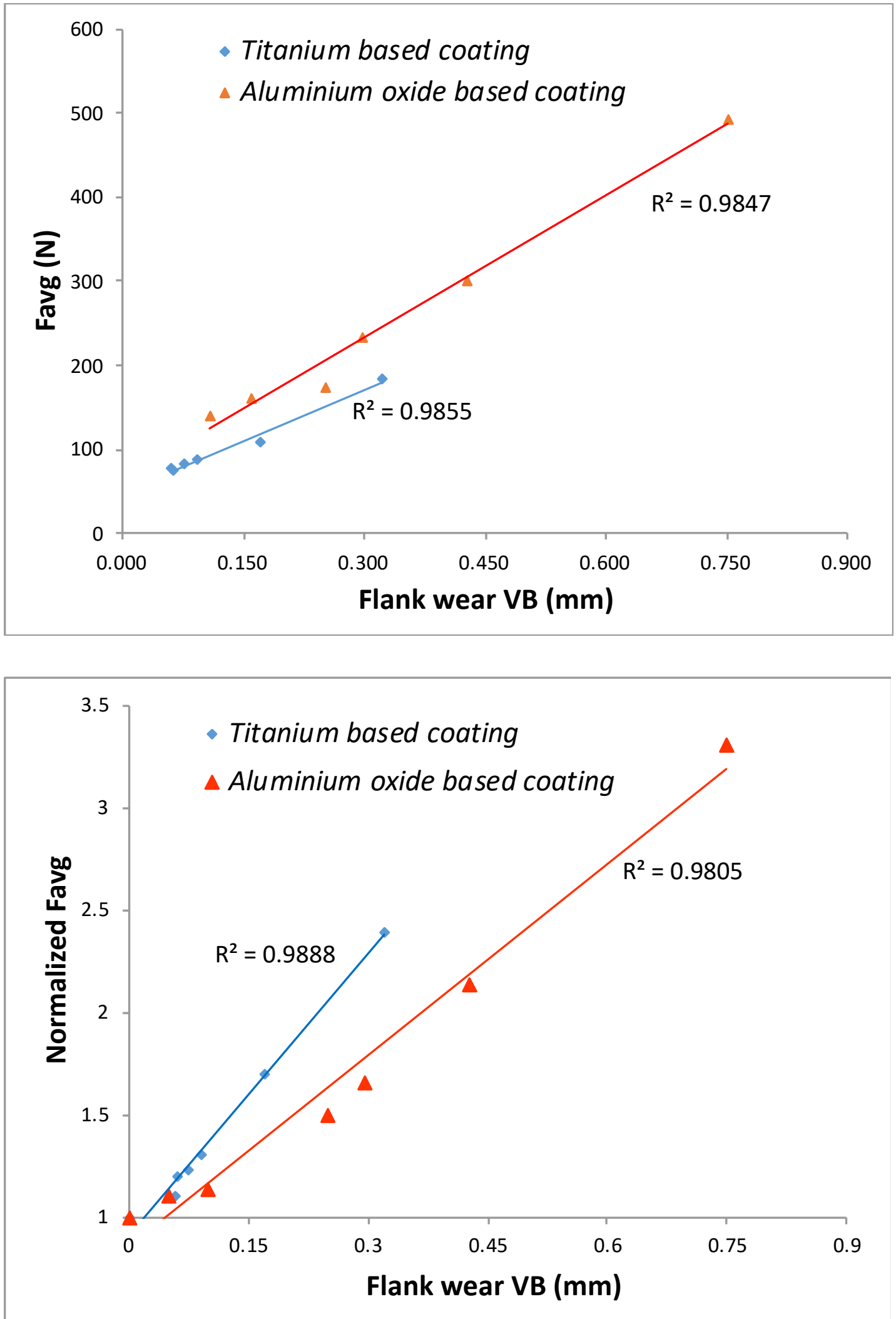

Figure 11: Correlation of cutting forces with flank wear, for ( $a$ - top) measured values and (bbottom) normalized forces 


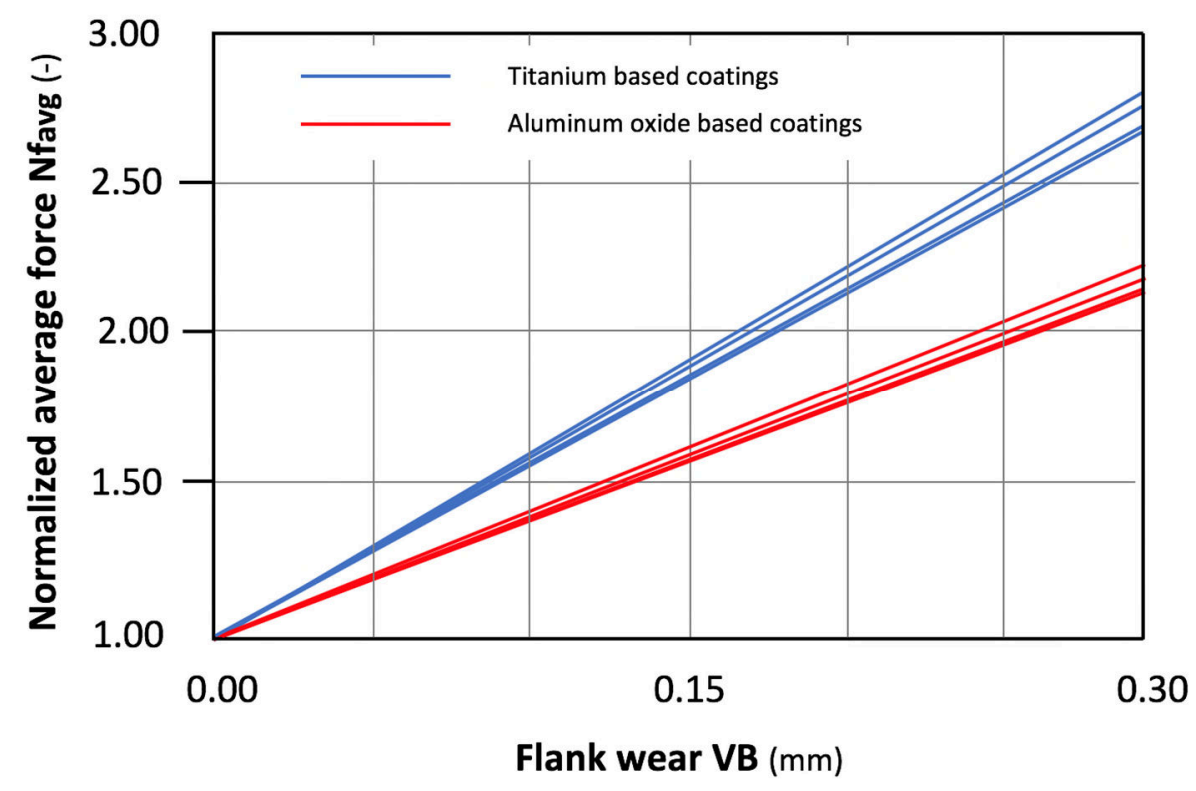

Figure 12: Normalized cutting force for a number of different process parameters

The approach described was repeated for all the experiments performed, and figure 12 presents the accumulated results. Two interesting results can be concluded:

- There is a characteristic linear curve correlating the normalized force with the flank wear. This curve is linear and is not greatly affected by the process parameters

- The slope of the curve is affected by the coating type of the cutting tool.

Such characteristic curve can be described by the following equation:

$N F a v g=c_{f} * V B$

(equation 1)

Where NFavg is the average cutting force, $c_{f}$ is the correlation coefficient (in $\mathrm{mm}^{-1}$ ) and $V B$ is the flank wear (in $\mathrm{mm}$ ).

The correlation coeficient can be easily estimated with a minimum number of experiments, since $\mathrm{R}^{2}$ was always exceeding 0.98 in the experiments performed. Only one curve needs to be defined for specific combinations of workpiece material and cutting tool cladding material. 


\section{Calculation of the reliability and the remaining life of the cutting tool}

Having established the linear relationship between the normalized cutting force and the flank wear, the number of experiments required for setting the relationships required for using the approach can be minimised. The following experimental setup is thus required:

- A minimum of three to four cutting experiments where forces are measured. First experiment should with the cutting tool being brand new, and the following ones after set time increments. For each time increment the flag wear needs to be measured for calculating the correlation coefficient (equation 1)

- A minimum number of experiements per process parameters combinations for establishing the regression functions. There is no need for measuring the flank wear.

In the following paragraphs, the above mentioned approach is presented as an example for the two types of cutting tools used.

The normalized cutting forces for the experiments conducted are presented in figures 13 and 14 that form the basis for extracting the response sufraces. Quadratic polynomials were selected for fitting the results. Based on these equations, response surfaces at different time are plotted are shown in Figure 15. Influences of cutting conditions with time can be seen from response surfaces, which indicate same results with experiments data. Typical pattern between cutting force and cutting conditions are clearly shown, but it should also be noted that surfaces are not that smooth due to limited points measured in the experiments, therefore actual values between these points may different from response surfaces. 


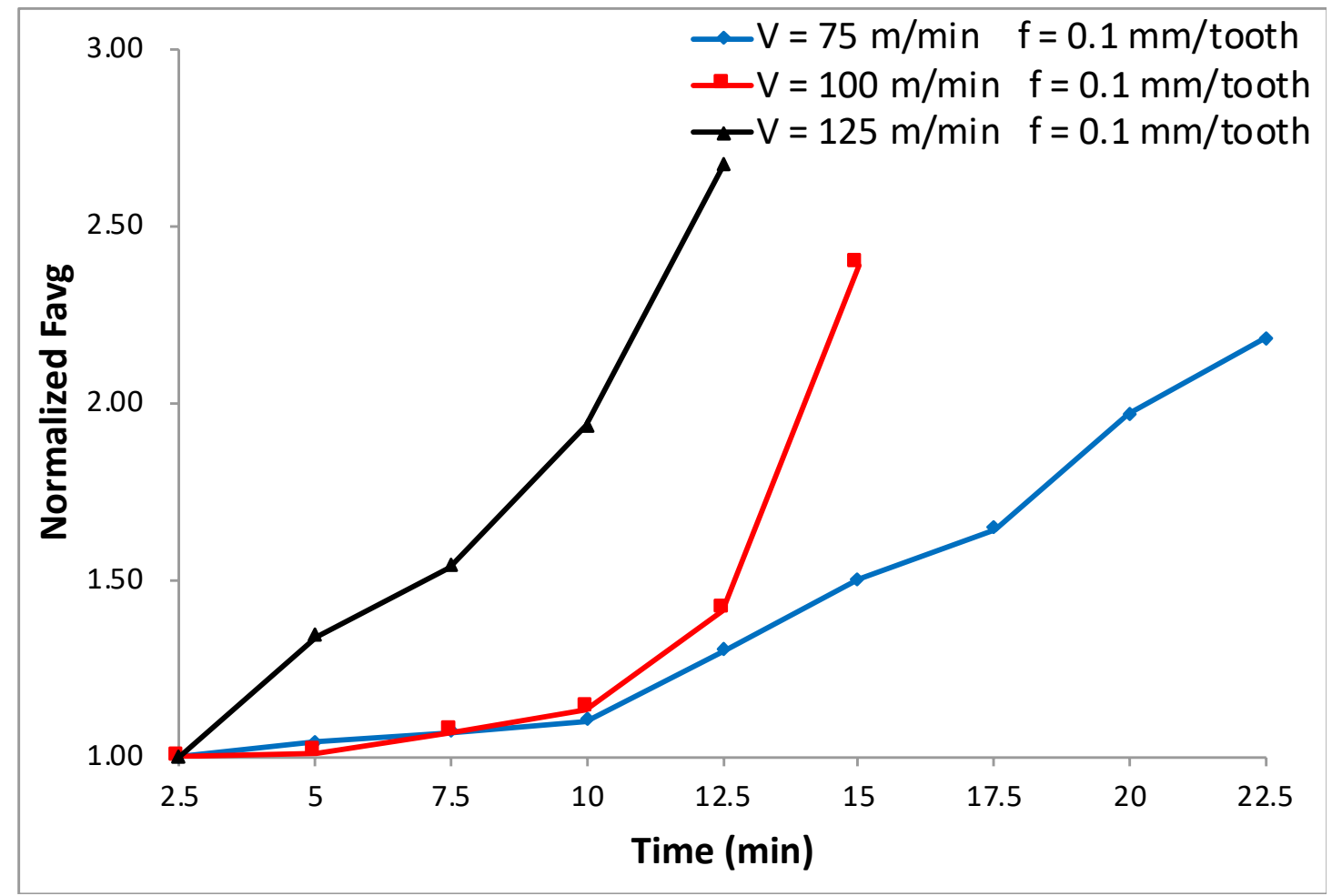

Figure 13: Relationship between normalized average cutting force and time of titanium based coating insert with different cutting conditions (for steady feed)

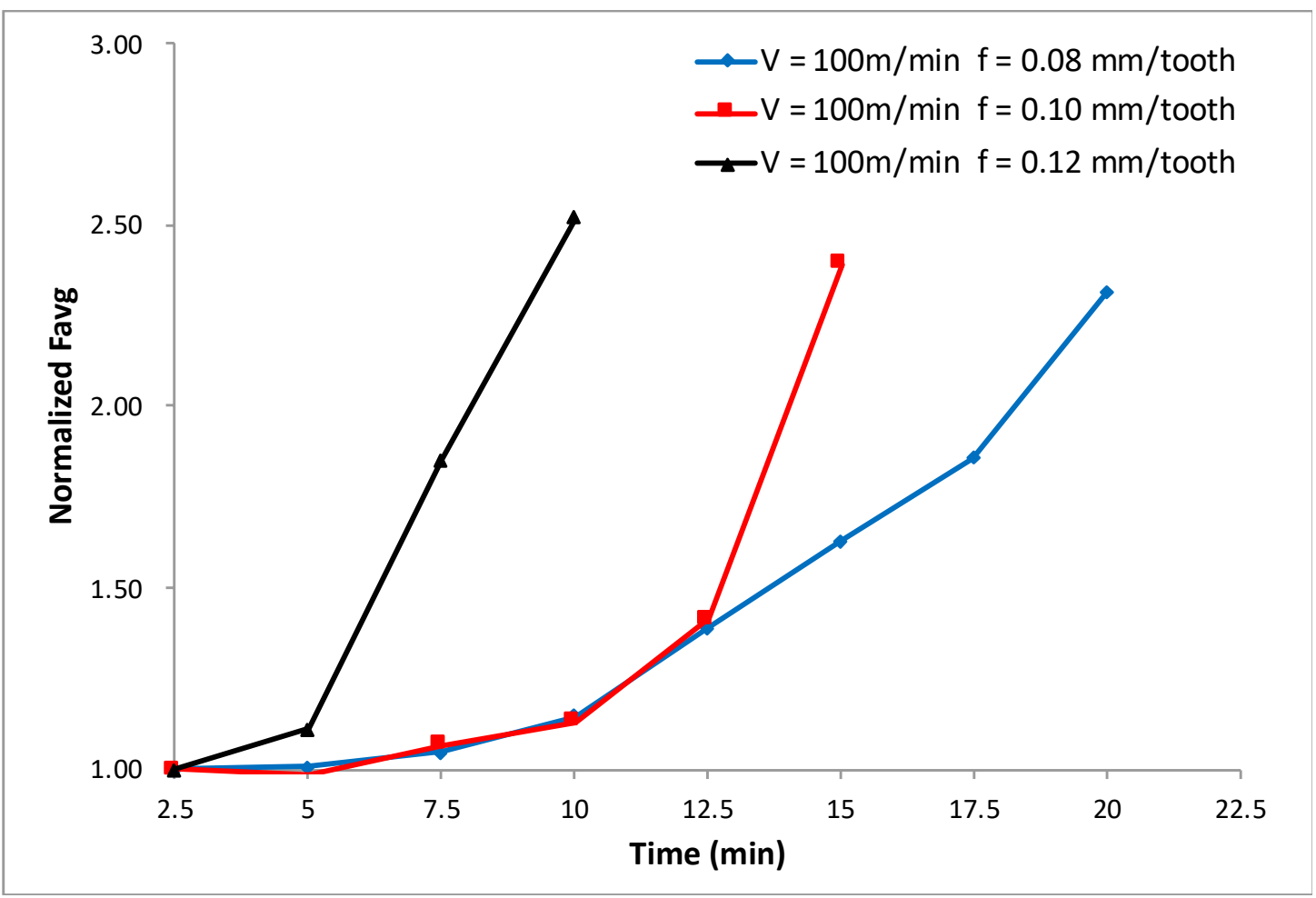

Figure 14: Relationship between normalized average cutting force and time of titanium based coating insert with different cutting conditions (for steady cutting speed) 


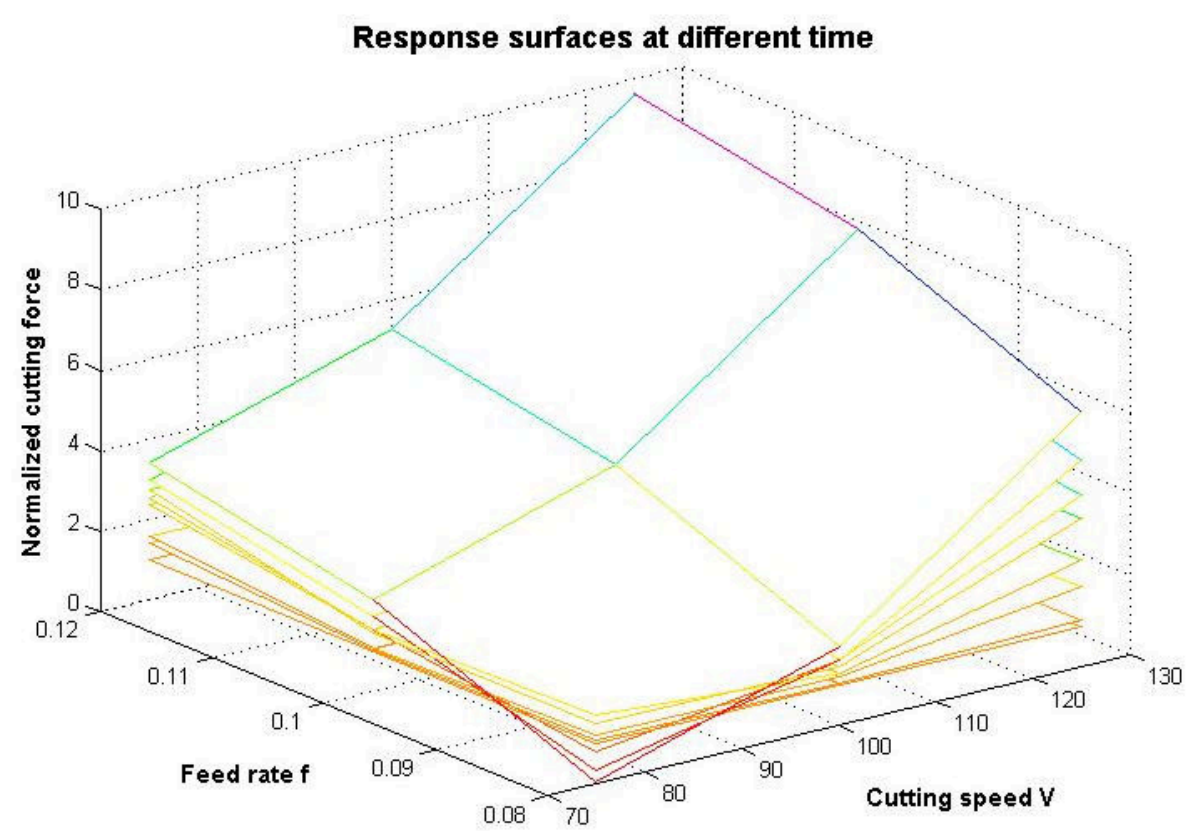

Figure 15: Response surfaces at different time

Following the process highlighted in figure 5, the quasi static probabilistic analysis follows. In the present analysis, the monte-carlo simulation approach has been selected for calculating the probability of failure and reliability for different cutting speeds. The probability of failure can be seen as the probability for which a limit state for a system is exceeded. This can be expressed for a multi-variable system $\mathrm{X}=\left\{\mathrm{x}_{1}, \mathrm{X}_{2}, \mathrm{X}_{3}, \ldots \mathrm{X}_{\mathrm{k}}\right\}$ using Limit State Functions formulated as the difference between the supply and demand:

$g(X)=L(X)-V(X)$

(equation 2)

Where $\mathrm{L}$ is the allowable limit, that is determined by standards and practices, and $\mathrm{V}$ the actual value of the response variable.

The n-dimensional vector X expresses the design variables with a known continuous joint distribution $f_{X}(X)$. Each functional requirement is expressed by $g_{j}(X)$, the limit-state function, which associates a negative value if the state identified by the variables results in failure, a positive for safe and a null value for the critical limit condition [40]. The probability of failure can be defined as the probability for the limit state condition to be unsatisfied: $\mathrm{P}_{\mathrm{f}}=\mathrm{P}[\mathrm{g}(\mathrm{X})<0]$. Hence the probability of failure can be rewritten as: 
$P_{f}=\int_{-\alpha}^{0} f_{g} d g=\int_{g(X)<0} f_{g} d g$

(equation 3)

The solution of this equation is not possible to be analytically calculated hence approximation methods are often employed characterised by different computational requirements and accuracy. Salonitis and Kolios [15] used first and second order reliability methods (FORM/SORM) as well as monte carlo simulations for the computation of the probability.

The limit state function in the present paper was estimated according to the analysis shown in figure 5 . The criterion set for the cutting forces was 2.5 times the cutting forces for a non-worn cutting tool. This corresponds to approximately a flank wear of $0.3 \mathrm{~mm}$, which is in aggreement to the ISO 3685:1993 standard for the case of cemented carbide tools where no irregular wear of the flank is observed.

The statistical properties of the variables, including both the input parameters and the process output were decided based on the literature review. Wager and Barash [41] and Hitomi and Nakamura [42] considered that the tool life present normal distribution, whereas Kwon et al. [43] considered Gaussian distribution. Lognormal or the Weibull distributions have been also suggested. Salonitis and Kolios [15] compared the importance of the chosen distribution on the calculated probability for Normal, Lognormal and Weibull highlighting that the type of probability distribution does not have any significant effect. This was in aggreement to what Zhou and Wysk [44] predicted as well. Therefore in the present study, for simplification reasons, the normal distribution has been selected for describing the stochasticity of both input variables and output calculations.

Figure 16 presents the outcome of this analysis for feed rate $\mathrm{f}=0.10 \mathrm{~mm} /$ tooth. It is possible to predict remaining tool life at different time with different confidence. For example, for cutting condition of $\mathrm{V}=125 \mathrm{~m} / \mathrm{min}$ and $\mathrm{f}=0.10 \mathrm{~mm} /$ tooth, there is about $75 \%$ confidence of reliability when milling after eight minutes. Additionally, the higher the cutting speed, the higher the probability of failure and the lower of reliability, which subsequently results in lower reliability for remaining tool life. Figure 17 indicates probability of failure and reliability for different feed rate when cutting speed is 100 $\mathrm{m} / \mathrm{min}$. Similarly, it can be seen that with the increasing of feed rate, the probability of failure goes higher and the reliability decreases. 

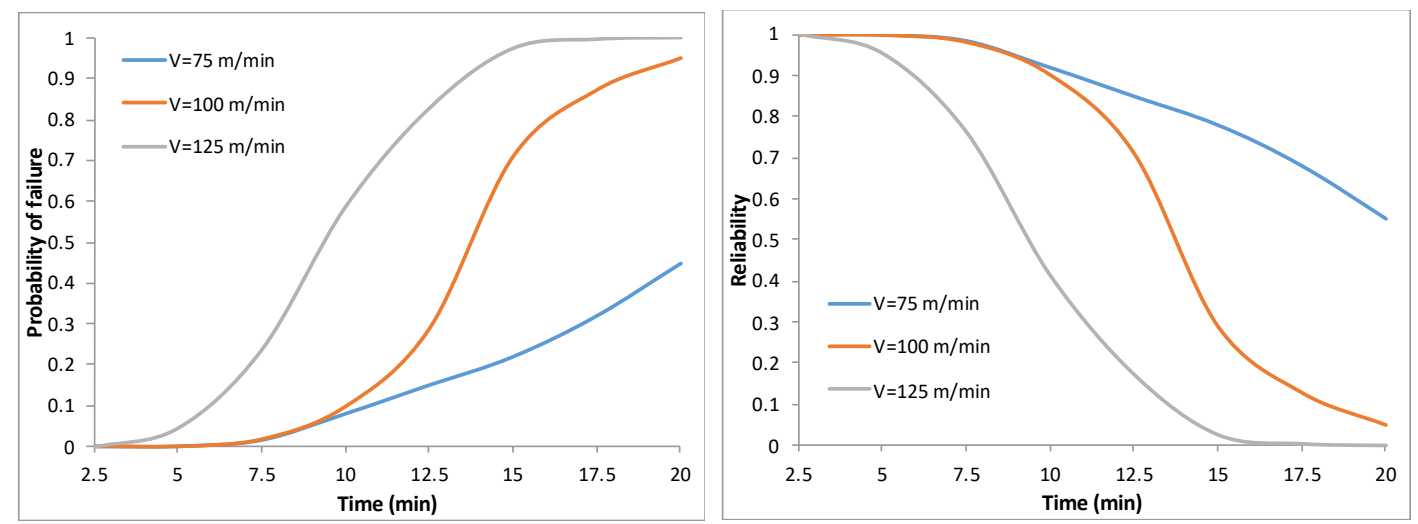

Figure 16: Probability of failure and reliability of different cutting speed ( $f=0.10 \mathrm{~mm} /$ tooth, depth of cut $=3 \mathrm{~mm}$, step over $=3 \mathrm{~mm}$ )
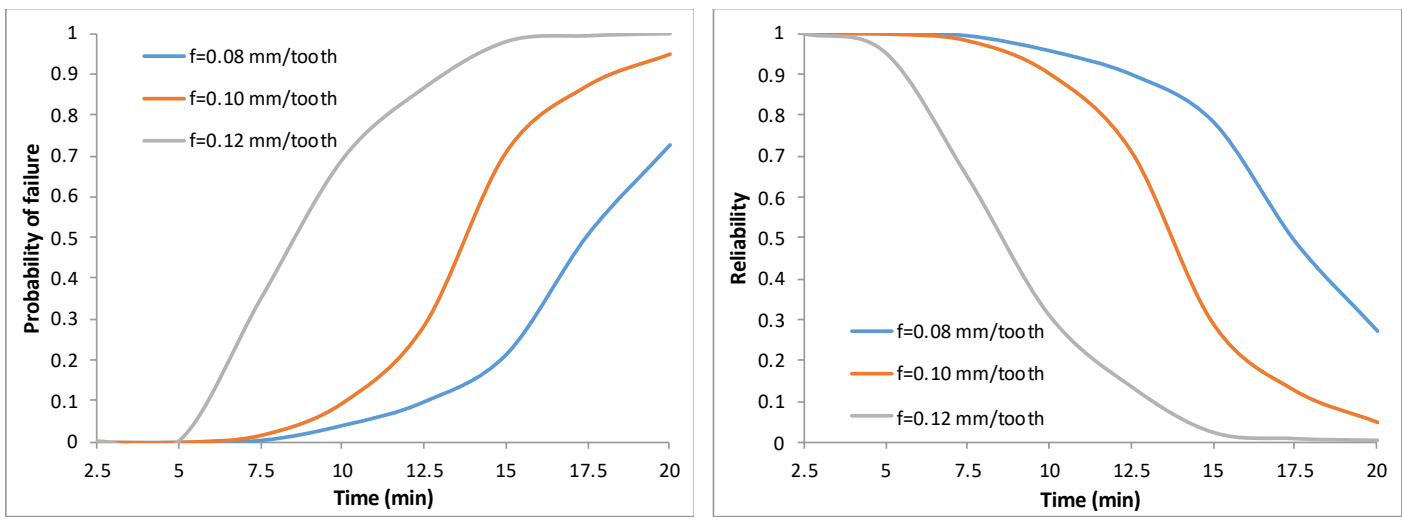

Figure 17: Probability of failure and reliability of different cutting speed $V=100 \mathrm{~m} / \mathrm{min}$, depth of cut $=3 \mathrm{~mm}$, step over $=3 \mathrm{~mm}$ )

For the validation of the predictions a further set of experiments was conducted for various combinations of the process parameters. A number of cutting tools with a titanium based coating were used and were stoped when the normalized force reached the critical value of 2.5 as this has been set for the limit state function. This was then compared to the predictions from figures 16 and 17 and eventually the flank wear was measured to validate the prediction of failure. Table 4 presents the results. It can be seen that all probabilities of failure are in the interval between $80 \%$ and $90 \%$, indicating that the cutting lifes have been used for almost all their useful life. The measurement of the average flank wear confirms this. 
Table 4: Actual tool failure time in experiments and corresponding probability of failure for titanium-based coating insert

\begin{tabular}{|c|c|c|}
\hline Cutting speed & \multicolumn{2}{|c|}{$V=100 \mathrm{~m} / \mathrm{min}$} \\
\hline Feed rate & $f=0.1$ & $f=0.12$ \\
\hline \multirow{3}{*}{$\begin{array}{r}\text { Time of failure m(min) } \\
\text { Probability of failure } \\
\text { Corresponding flank wear (mm) }\end{array}$} & 15.5 & 12 \\
\hline & $82 \%$ & $85 \%$ \\
\hline & 0.26 & 0.27 \\
\hline \multirow{5}{*}{$\begin{array}{r}\text { Feed rate } \\
\text { Cutting speed } \\
\text { Time of failure (min) } \\
\text { Probability of failure } \\
\text { Corresponding flank wear (mm) }\end{array}$} & \multicolumn{2}{|c|}{$\mathrm{f}=0.1 \mathrm{~mm} /$ tooth } \\
\hline & $V=100$ & $V=125$ \\
\hline & 17 & 12 \\
\hline & $85 \%$ & $80 \%$ \\
\hline & 0.25 & 0.28 \\
\hline
\end{tabular}

\section{Discussion of proposed methodology}

The proposed methodology allows the assesment of the remaining life of a cutting tool using a minimum number of experiments for setting the reliability curves. However, a number of assumptions can have an impact on the resulting curves. A sensitivity analysis thus is important in order to have a clear view of the importance of the various variables and simulation assumptions.

\subsection{Distribution properties}

Stochasticity in variables can have an impact on the accuracy of predictions. Figure 18 shows the impact of stochasticity of feed rate. The predictions can be considered robust, as changing the feed rate by $20 \%$ has a minimum impact on the probabibility of failucr with maximum deviation being less than $10 \%$. 


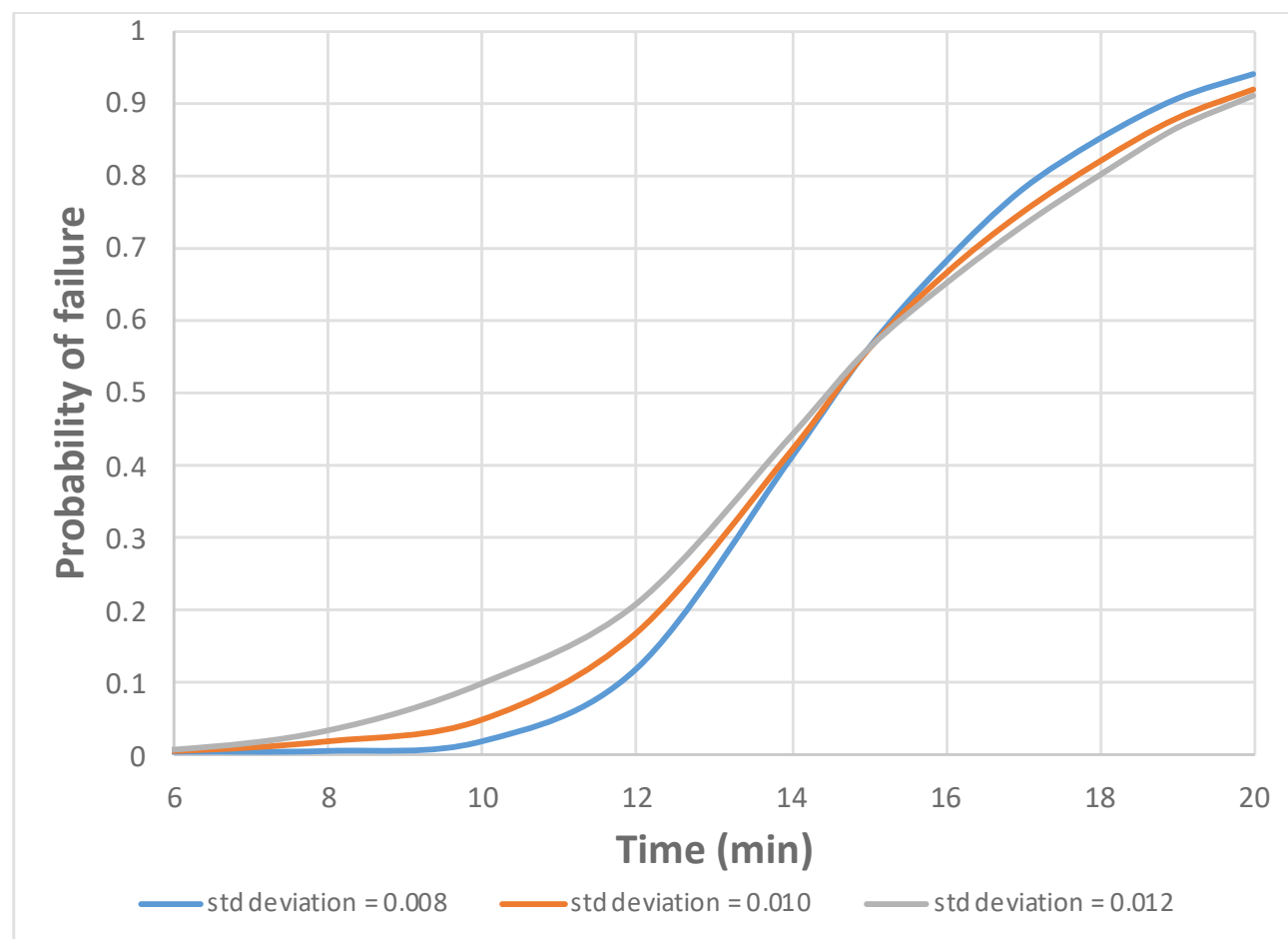

Figure 18: Standard deviation of feed rate ranges from 0.008 to 0.012 when $V=100 \mathrm{~m} / \mathrm{min}, f=0.1$ $\mathrm{mm} /$ tooth, depth of cut $=3 \mathrm{~mm}$, step over $=3 \mathrm{~mm}$

\subsection{Limit state stochasticity}

The limit state function, that describes the failure criteria, was set to 2.5 of the normalized force, reflecting the extensively used failure criteria of flank wear for milling tool is $\mathrm{V}_{\mathrm{B}}=0.3 \mathrm{~mm}$ according to ISO $8688-1 \backslash-2: 1989$. However, this limit state criterion is stochastic by nature as well. The value, as described, is calculated following the experimental analysis that results to figure 10. For the normalized force of titanium based coating inserts it is approximately 2.7 and aluminium oxide based coating insert is around 2.2. Increasing the limit state function results in lower probabilities of failure, thus in more optimistic predictions of the cutting tool life. Assuming that the confidence level of replacing a new tool is when the probability of failure reaches $60 \%$, therefore the tool life could increase by about 50 seconds when the limit state value changes from 2.5 to 2.7 (figure 19). To conclude, limit state value has great impact on cutting tools reliability assessment. For more accurate estimation of remaining life of a cutting tool, it is better to know the specific relationship between flank wear and cutting force, and then failure criteria of normalized force can be adjusted to a more proper value. This requires running a higher number of experiments for calculating figure 12. 


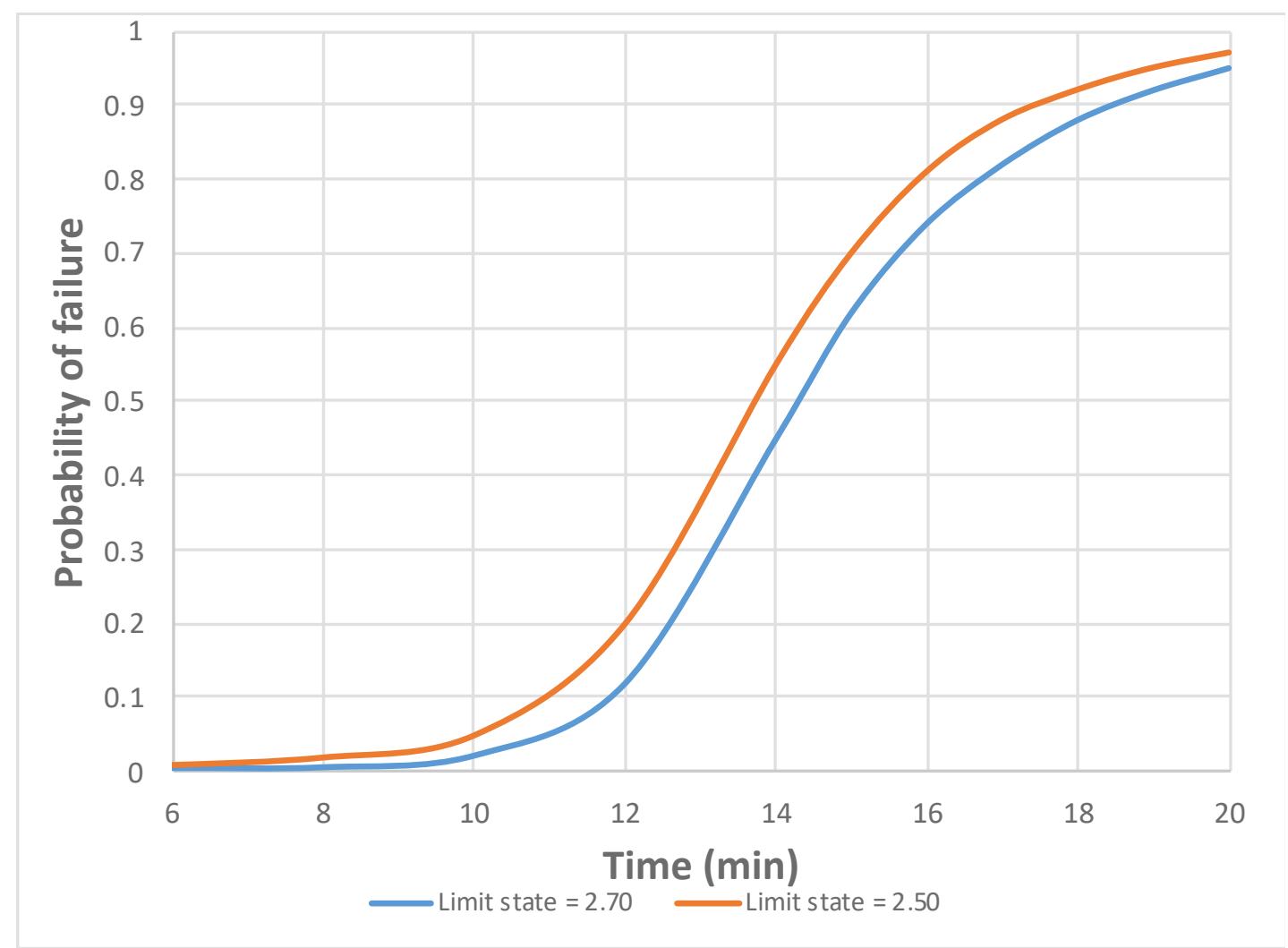

Figure 19: Influence of limit state values when $V=100 \mathrm{~m} / \mathrm{min}$ and $f=0.1 \mathrm{~mm} /$ tooth

\section{Conclusions}

In this paper, a new approach that takes cutting force into account to estimate tool reliability is proposed. Before proposing the methodology, tool wear mechanism and tool force progression have been reviewed from relevant literature. The simulation results indicate the possibilities to assess remaining tool life when milling Ti-6Al-4V alloy. Probabilities of failure are all within a specific range when an insert fails, which might be an indicator for estimation. But meanwhile, further investigations on factors of influences are mentioned as well.

A concept mapping was presented to show the most common wear mechanisms existing in titanium alloy machining. Adhesive wear, diffusion wear, abrasive wear and oxidation wear are the most common wear mechanisms when machining titanium alloys. Cutting force progression during titanium machining is reviewed as well. A table which shows the general relationship between cutting force, flank wear and cutting conditions is summarized in the paper. 
Two cutting tool inserts, one with titanium based coating and one with aluminium oxide based coating, were used. Flank wear and average cutting forces of both inserts were measured. A typical three-stage pattern diagram of flank wear for both inserts is presented, and cutting force progression performs the same pattern with that of flank wear.

According to the results analysed, titanium based coating insert has better wear resistance and results in lower average cutting forces than that of aluminium oxide based coating insert when machining Ti-6Al-4V alloy. Finally, a linear relationship between flank wear and average cutting force is found in the paper, which indicates the possibilities to assess cutting tool reliability by monitoring cutting force.

Based on these findings, average cutting force, instead of flank wear, is introduced in this paper as the basis of reliability calculation. The method developed allows for the estimation of the reliability of the cutting tools without requiring the measurement of the flank wear. Influences of standard deviation and limit state value are discussed as well. Generally, standard deviation has slight influence on the probability of failure but limit state value affects the probability of failure greatly.

The analysis presented did not include the recognition of the tool wear mechanisms, as this is not within the scope of the present study. Obviously the correlation of the forces with the tool wear is applicable only in the case of gradual tool wear increasing with the cutting time, that is characteristic for the abrasisve/adhesive wear mechanisms. Future work will also include SEM inspections of worn tools and spectrometry analysis for identifying the different types of wear.

\section{Acknowledgements}

The authors would like to acknowledge Cranfield University MSc Student Dai Xin Chen for the analysis of the experimental results.

\section{References}

[1] Wei S, Savko M (2009) Titanium alloys: modelling of microstructure, properties and applications, 1st ed, Woodhead Publising Limited, Cambridge, UK. 
[2] Ezugwu E (2005) Key improvements in the machining of difficult-to-cut aerospace superalloys, International Journal of Machine Tools and Manufacture 45(12):1353-1367

[3] Ezugwu E, Wang Z (1997) Titanium alloys and their machinability-a review, Journal of Materials Processing Technology 68(3):262-274.

[4] Klocke F, Eisenblaetter G (1997) Dry cutting, CIRP Ann. Manuf. Technol. 46 (2):519526.

[5] Grzesik W (2008) Advanced Machining Processes of Metallic Materials.1st Edition

[6] Tapoglou N, Lopez M, Cook I, Taylor C (2017) Investigation of the Influence of CO2 Cryogenic Coolant Application on Tool Wear, Procedia CIRP 63:745 - 749

[7] Bayer RG (2002) Wear analysis for engineers, Hnb Pub., New York

[8] Bermingham M, Palanisamy S, Dargusch M (2012) Understanding the tool wear mechanism during thermally assisted machining Ti-6Al-4V, International Journal of Machine Tools and Manufacture 62:62-87

[9] Zhang S, Li J, Deng J, Li Y (2009) Investigation on diffusion wear during high-speed machining Ti-6Al-4V alloy with straight tungsten carbide tools, The International Journal of Advanced Manufacturing Technology 44(1-2):17-25

[10] Xu X, Yu Y, Huang H (2003) Mechanisms of abrasive wear in the grinding of titanium (TC4) and nickel (K417) alloys, Wear 255(7):1421-1426

[11] Jawaid A, Che-Haron C, Abdullah A (1999) Tool wear characteristics in turning of titanium alloy Ti-6246, Journal of Materials Processing Technology 92: 329-334.

[12] Wang Z, Rahman M, Wong Y (2005) Tool wear characteristics of binderless CBN tools used in high-speed milling of titanium alloys, Wear 258(5):752-758

[13] Nouari M, Ginting A (2006) Wear characteristics and performance of multi-layer CVD-coated alloyed carbide tool in dry end milling of titanium alloy, Surface and Coatings Technology 200(18): 5663-5676

[14] Astakhov VP, Davim JP (2008) Tools (geometry and material) and tool wear, in Machining: fundamentals and recent advances, Springer, pp. 29-57 
[15] Salonitis K, Kolios A (2014) Reliability assessment of cutting tool life based on surrogate approximation methods. International Journal of Advanced Manufacturing Technology 71:1197-1208

[16] Smith, G. T. (2008), Cutting tool technology, Springer-Verlag London

[17] Wiklund H (1998) Bayesian and regression approaches to on-line prediction of residual tool life. Quality and Reliability Engineering International 14(5):303-309

[18] Sakharov GN, Ilinykh V, Konyukhov Yu V (1990) Improvement of fastening elements in an assembled cutting tool. Soviet Engineering Research 10(11):102-103

[19] Yu Pimenov D, Guzeev VI, Krolczyk G, Mozammel Mia, Wojciechowski S (2018) Modeling flatness deviation in face milling considering angular movement of the machine tool system components and tool flank wear. Precision Engineering 54:327-337

[20] Marcelo Mendes de Aguiar, Anselmo Eduardo Diniz, Robson Pederiva (2013). Correlating surface roughness, tool wear and tool vibration in the milling process of hardened steel using long slender tools. International Journal of Machine Tools and Manufacture 68:1-10

[21] Wojciechowski S (2011) Machined surface roughness including cutter displacements in milling of hardened steel, Metrology and Measurement Systems XVIII (3):429 - 440.

[22] El Wardany TI, Elbestawi MA (1997) Prediction of Tool Failure Rate in Turning Hardened Steels. International Journal of Advanced Manufacturing Technology 13(1):116.

[23] Trent EM (1963) Cutting steel and iron with cemented carbide tools. Part I. An analysis of tool wear. J Iron Steel Inst 201:847-855.

[24] Naerheim Y, Trent EM (1977) Diffusion wear of cemented carbide tools when cutting steel at high speeds. Metals Technology 4:548-556

[25] Ramalingam S, Wright PK (1981) Abrasive wear in machining: experiment with material of controlled microstructure. ASME Journal of Engineering Materials and Technology 103:151-156 
[26] Sarhan A, Sayed R, Nassr A, El-Zahry R (2001) Interrelationships between cutting force variation and tool wear in end-milling, Journal of Materials Processing Technology 109(3):229-235

[27] Ibrahim G, Haron, C. C. and Ghani, J. (2009), "Progression and wear mechanism of CVD carbide tools in turning Ti-6Al-4V ELI", International Journal of Mechanical and Materials Engineering, vol. 4, no. 1, pp. 35-41.

[28] Jawaid, A., Sharif, S. and Koksal, S. (2000), "Evaluation of wear mechanisms of coated carbide tools when face milling titanium alloy", Journal of Materials Processing Technology, vol. 99, no. 1, pp. 266-274

[29] Davim PJ, Baptista MA (2000) Relationship between cutting force and PCD cutting tool wear in machining silicon carbide reinforced aluminium, Journal of Materials Processing Technology 103(3): 417-423.

[30] Remadna M, Rigal JF (2006) Evolution during time of tool wear and cutting forces in the case of hard turning with CBN inserts, Journal of Materials Processing Technology 178(1):67-75

[31] Costes J, Guillet Y, Poulachon G, Dessoly M (2007) Tool-life and wear mechanisms of CBN tools in machining of Inconel 718, International Journal of Machine Tools and Manufacture 47(7):1081-1087.

[32] Sun J, Wong Y, Rahman M, Wang Z, Neo K, Tan C, Onozuka H (2006) Effects of coolant supply methods and cutting conditions on tool life in end milling titanium alloy, Machining Science and Technology 10(3): 355-370

[33] Caprino G, Nele L, Santo L (1996) Effect of tool wear on cutting forces in the orthogonal cutting of unidirectional glass fibre-reinforced plastics, Composites Part A: Applied Science and Manufacturing 27(5):409-415

[34] Li H, Zeng H, Chen X (2006) An experimental study of tool wear and cutting force variation in the end milling of Inconel 718 with coated carbide inserts, Journal of Materials Processing Technology 180(1):296-304.

[35] Kuljanic E, Sortino M (2005) TWEM, a method based on cutting forces-monitoring tool wear in face milling, International Journal of Machine Tools and Manufacture 45(1):29-34 
[36] Carlson TE, Strand F (1992) A statistical model for prediction of tool life as a basis for economical optimization of the cutting process. Annals of CIRP 41(1):79-82

[37] Salonitis K, Kolios A (2013) P Reliability assessment of cutting tools life based on advanced approximation methods. Procedia CIRP 8:397-402

[38] International Standardization Organization (1993). Tool-life testing with singlepoint turning tools, ISO 3685:1993

[39] Wojciechowski S, Twardowski P (2012). Tool life and process dynamics in high speed ball end milling of hardened steel. Procedia CIRP 1, pp. 289 - 294

[40] Choi SK, Grandi RV (2007) Reliability-Based Structural Design, Springer-Verlag, London.

[41] Wager JG, Barash MM (1971) Study of the distribution of the life of HSS tools. Journal of Engineering for Industry, Transactions of the ASME 93:1044-1050

[42] Hitomi K, Nakamura N, Inoue S (1979) Reliability analysis of cutting tools. Journal of Engineering for Industry-Transactions of the ASME 101:185-190.

[43] Kwon WT, Park JS, Kang S (2005) Effect of group IV elements on the cutting characteristics of $\mathrm{Ti}(\mathrm{C}, \mathrm{N})$ cermet tools and reliability analysis. Journal of Materials Processing Technology 166(1):9-14.

[44] Zhou C, Wysk RA (1992) An Integrated System for Selecting Optimum Cutting Speeds and Tool Replacement Times. International Journal of Machine Tools and Manufacturing 32(5):695-707 
2020-01-04

Force-based reliability estimation of remaining cutting tool life in titanium milling

Salonitis, Konstantinos

Springer

Salonitis K, Kolios A. (2020) Force-based reliability estimation of remaining cutting tool life in titanium milling. International Journal of Advanced Manufacturing Technology, Volume 106, February 2020, pp. 3321-3333

https://doi.org/10.1007/s00170-019-04883-9

Downloaded from Cranfield Library Services E-Repository 